TITE

\title{
Cobalt-catalyzed carboxylation of propargyl acetates with carbon dioxide.
}

$\operatorname{AUTHOR}(S)$ :

Nogi, Keisuke; Fujihara, Tetsuaki; Terao, Jun; Tsuji, Yasushi

CITATION:

Nogi, Keisuke ... [et al]. Cobalt-catalyzed carboxylation of propargyl acetates with carbon dioxide.. Chemical Communications 2014, 50(86): 13052-13055

ISSUE DATE:

2014-06-05

URL:

http://hdl.handle.net/2433/200259

\section{RIGHT:}

This journal is (C) The Royal Society of Chemistry 2014.; This is not the published version. Please cite only the published version.; この論文は 出版社版でありません。引用の際には出版社版をご確認ご利用くださ い。 


\section{COMMUNICATION}

\section{Cobalt-catalyzed carboxylation of propargyl acetates with carbon dioxide}

Received 00th January 2012, Accepted 00th January 2012

\author{
Keisuke Nogi, Tetsuaki Fujihara,* Jun Terao and Yasushi Tsuji*
}

The cobalt-catalyzed carboxylation of propargyl acetates with $\mathrm{CO}_{2}$ (1 atm) is described. The reaction proceeds at room temperature with Mn powder as a reducing reagent. Various propargyl acetates are converted to the corresponding carboxylic acids in good to high yields.

Carbon dioxide $\left(\mathrm{CO}_{2}\right)$ is an environmentally friendly raw material and its utilization as a sustainable carbon source is one of the most important challenges in homogeneous transition-metal catalysis. ${ }^{1}$ In particular, $\mathrm{C}-\mathrm{C}$ bond forming reactions using $\mathrm{CO}_{2}$ are the most promising. ${ }^{1 \text { a }}$ Reactions using highly reactive Grignard and organolithium reagents with $\mathrm{CO}_{2}$ are fundamental for the $\mathrm{C}-\mathrm{C}$ bond formation, but chemoselectivity with these reagents is very poor. In contrast, less reactive arylboronic esters $^{2 \mathrm{a}-\mathrm{c}}$ and arylzinc compounds $^{2 \mathrm{~d}, \mathrm{e}}$ were found to react with $\mathrm{CO}_{2}$ with good chemoselectivity in the presence of a transition-metal catalyst. However, all these organometallic compounds are mainly synthesized from the corresponding aryl halides. Thus, the direct carboxylation of aryl halides is more straightforward and efficient. We recently reported the nickel-catalyzed direct carboxylation of aryl and vinyl chlorides with $\mathrm{CO}_{2}$ (1 atm) at room temperature, ${ }^{3 \mathrm{a}, \mathrm{b}}$ while carboxylations of more reactive aryl bromides ${ }^{3 \mathrm{c}}$ and benzyl chlorides $^{3 \mathrm{~d}}$ as well as inert $\mathrm{C}-\mathrm{O}$ bonds $^{3 \mathrm{e}}$ were also reported. ${ }^{4}$

Reactions of allylic and propargylic compounds with $\mathrm{CO}_{2}$ afford a variety of unsaturated carboxylic acids. To date, these transformations consume a stoichiometric amount of the corresponding Grignard, organolithium, or other metal reagents. ${ }^{5}$ These reactions also have problems in regioselectivity and chemoselectivity.

Therefore, the development of a new selective methodology is highly desirable. Allyl and propargyl esters (typically, acetates or carbonates) are well known as efficient electrophiles in transitionmetal-catalyzed $\mathrm{C}-\mathrm{C}$ bond forming reactions. ${ }^{6}$ In order to utilize these electrophiles with $\mathrm{CO}_{2}$, umpolung ${ }^{7}$ reactivity of these esters is crucial. Actually, the reactions of allyl esters with $\mathrm{CO}_{2}$ were carried out under electrochemical conditions in the presence of $\mathrm{Pd}$ or $\mathrm{Ni}$ catalysts; ${ }^{8}$ however, the yields and regioselectivities were low. Furthermore, there is no precedent for the carboxylation of propargyl esters with $\mathrm{CO}_{2} .{ }^{9}$ Herein, we report the Co-catalyzed carboxylation of propargyl acetates with $\mathrm{CO}_{2}$ utilizing $\mathrm{Mn}$ powder as a reducing agent. Various propargyl acetates were converted to the corresponding carboxylic acids under $1 \mathrm{~atm} \mathrm{CO}_{2}$ at room temperature.

The carboxylation of propargyl acetate 1a was carried out under $\mathrm{CO}_{2}(1 \mathrm{~atm})$ at room temperature in the presence of $\mathrm{CoI}_{2}(\mathrm{phen})^{10}(\mathrm{phen}$
Table 1 Reaction optimization ${ }^{a}$

\begin{tabular}{|c|c|c|c|c|}
\hline \multirow[b]{2}{*}{$\begin{array}{r}\mathrm{TMS} \\
\overline{\mathbf{1 a}}\end{array}$} & \multirow{2}{*}{$K_{\mathrm{OAC}}^{\mathrm{Me}}$} & \multicolumn{3}{|l|}{$\mathrm{CO}_{2}(1 \mathrm{~atm}$, closed $)$} \\
\hline & & $\begin{array}{l}\text { Mn (3.0 equiv) } \\
\text { DMA, rt, } 20 \mathrm{~h}\end{array}$ & $\begin{array}{l}\text { 2) } \mathrm{TMSCHN}_{2} \\
\mathrm{Et}_{2} \mathrm{O} / \mathrm{MeOH}\end{array}$ & 2a-Me \\
\hline Entry & & $\begin{array}{l}\text { alyst System: Chang } \\
\text { ndard Conditions }\end{array}$ & rom the & $\begin{array}{l}\text { Yield of 2a-Me } \\
(\%)^{b}\end{array}$ \\
\hline 1 & no & & & $83(82)^{c}$ \\
\hline 2 & & thout $\mathrm{CoI}_{2}$ (phen) & & 0 \\
\hline 3 & & $\mathrm{I}_{2}$ in place of $\mathrm{CoI}_{2}(\mathrm{ph}$ & & 0 \\
\hline 4 & & thout $\mathrm{Mn}$ powder & & 0 \\
\hline 5 & & a Powder $(0.60 \mathrm{mmol}$ & .2 equiv) & 74 \\
\hline 6 & & $\mathrm{Br}_{2}(\mathrm{phen})$ in place of & $\mathrm{oI}_{2}$ (phen) & 80 \\
\hline 7 & & $\mathrm{I}_{2}$ (bpy) in place of $\mathrm{C}$ & (phen) & 76 \\
\hline 8 & & $\mathrm{I}_{2}\left(\mathrm{PPh}_{3}\right)_{2}$ in place of & $\mathrm{I}_{2}$ (phen) & 23 \\
\hline 9 & & $\mathrm{I}_{2}(\mathrm{dppe})$ in place of & $\mathrm{I}_{2}$ (phen) & 0 \\
\hline 10 & & in place of Mn & & 41 \\
\hline 11 & & in place of $\mathrm{Mn}$ & & 57 \\
\hline $12^{d}$ & & $\mathrm{Cl}_{2}\left(\mathrm{PPh}_{3}\right)_{2}$ in place of & $\mathrm{OI}_{2}$ (phen) & 7 \\
\hline
\end{tabular}

${ }^{a}$ Reaction conditions; 1a $(0.50 \mathrm{mmol}), \mathrm{CoI}_{2}$ (phen) $(0.025 \mathrm{mmol}, 5.0 \mathrm{~mol} \%)$, Mn powder (1.5 mmol, 3.0 equiv), $\mathrm{CO}_{2}(1 \mathrm{~atm})$, in DMA $(0.50 \mathrm{~mL})$, at room temperature for $20 \mathrm{~h} .{ }^{b}$ Determined by GC analysis. ${ }^{c}$ Isolated yield of 2a. ${ }^{d}$ With $\mathrm{Et}_{4} \mathrm{NI}(0.05 \mathrm{mmol}, 10 \mathrm{~mol} \%)$.

= 1,10-phenanthroline) and Mn powder (3.0 equiv) in DMA ( $N, N$ dimethylacetamide) (Table 1). The yield of the corresponding carboxylic acid (2a) was determined by gas chromatographic (GC) analysis after derivatization to the corresponding methyl ester (2aMe). Under the standard conditions, 2a-Me was obtained in $83 \%$ yield (entry 1). Compound 2a was isolated from the reaction mixture in $82 \%$ yield. Without $\mathrm{CoI}_{2}$ (phen), 2a-Me was not obtained (entry 2 ). In the absence of phen (i.e., $\mathrm{CoI}_{2}$ as the catalyst), 1a was not converted (entry 3). Without the addition of Mn powder, the carboxylation did not proceed at all (entry 4). When the amount of Mn powder was reduced to 1.2 equiv, the yield of $\mathbf{2 a - M e}$ was decreased to $74 \%$ (entry 5). $\mathrm{CoBr}_{2}$ (phen) was also a good catalyst and afforded $2 \mathbf{a}-\mathbf{M e}$ in $80 \%$ yield (entry 6). Employing $\mathrm{CoI}_{2}$ (bpy) (bpy $=2,2$ '-bipyridine) as a catalyst, 2a-Me was obtained in $76 \%$ yield (entry 7 ). Thus, phen and bpy show comparable efficiency as the ligand. In contrast, $\mathrm{CoI}_{2}\left(\mathrm{PPh}_{3}\right)_{2}$ and $\mathrm{CoI}_{2}$ (dppe) (dppe = 1,2-diphenylphosphinoethane) suppressed the carboxylation considerably (entries 8 and 9). Other reducing agents such as $\mathrm{Zn}$ powder and $\mathbf{M g}$ turnings gave 2a-Me in only moderate yields (entries 10 and 11 ). $\mathrm{NiCl}_{2}\left(\mathrm{PPh}_{3}\right)_{2}$, which was an 
Table 2 Cobalt-catalyzed carboxylation of various propargyl acetates ${ }^{a}$

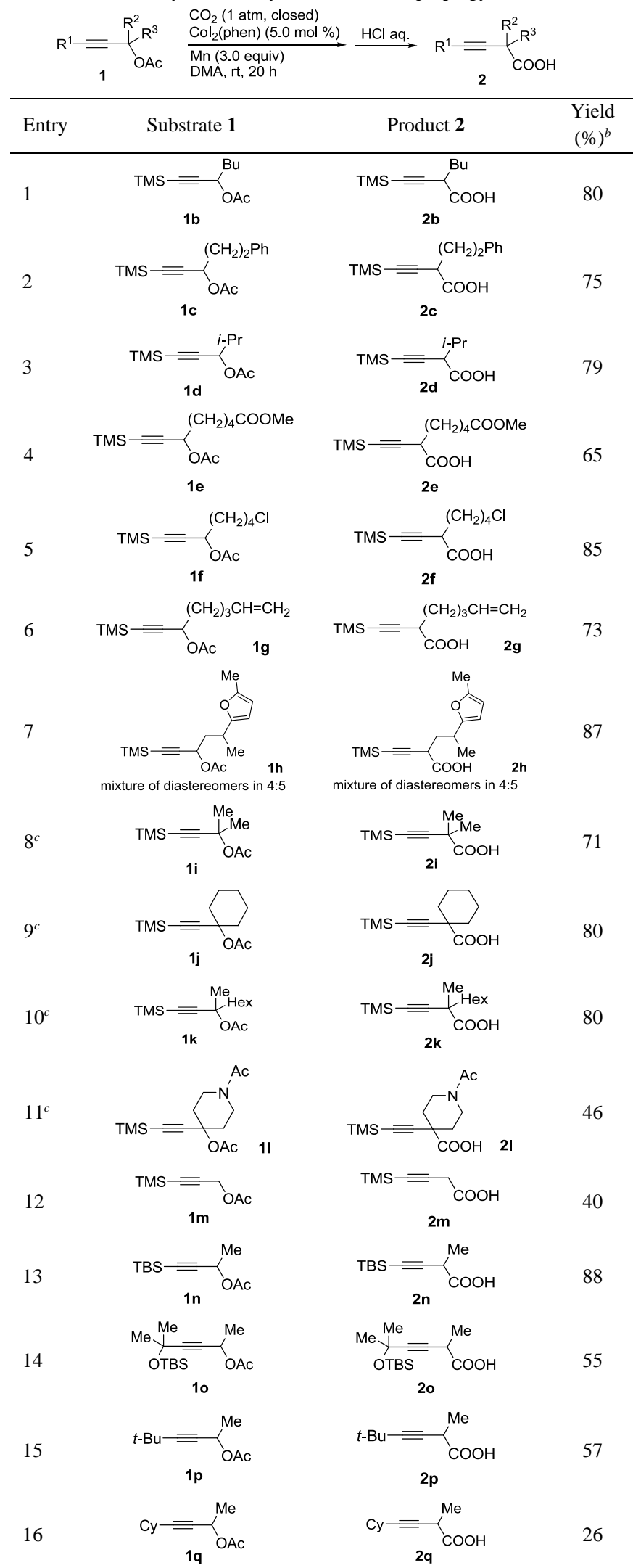

${ }^{a}$ Reaction conditions; propargyl acetate $(\mathbf{1}, 0.50 \mathrm{mmol}), \mathrm{CoI}_{2}$ (phen) $(0.025$ mmol, $5.0 \mathrm{~mol} \%)$, Mn powder ( $1.5 \mathrm{mmol}, 3.0$ equiv), $\mathrm{CO}_{2}(1 \mathrm{~atm})$, in DMA $(0.50 \mathrm{~mL})$, at room temperature for $20 \mathrm{~h} .{ }^{b}$ Isolated yield. ${ }^{c} \mathrm{CoI}_{2}$ (bpy) $(0.025 \mathrm{mmol}, 5.0 \mathrm{~mol} \%)$ was used as a catalyst.

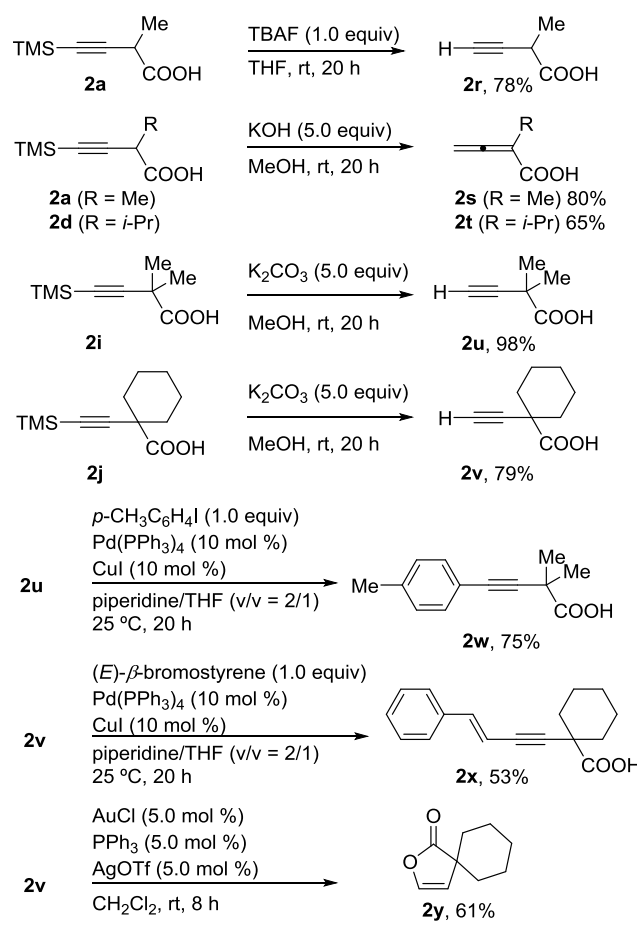

(a)

(b)

Scheme 1 Derivatization of carboxylated products.

efficient catalyst for the carboxylation of aryl chloride, ${ }^{3 a}$ did not show good catalytic activity (entry 12). Other nickel catalysts such as $\mathrm{NiBr}_{2}$ (bpy) and $\mathrm{NiI}_{2}$ (phen) were not efficient. With regard to the choice of solvent, 1,3-dimethyl-2-imidazolidinone (DMI) and DMF were also suitable, while reactions in THF and toluene afforded 2aMe in $26 \%$ and $0 \%$ yields, respectively (Table S1). ${ }^{11}$

The carboxylation of various propargyl acetates was carried out in the presence of $\mathrm{CoI}_{2}$ (phen) or $\mathrm{CoI}_{2}$ (bpy) as a catalyst (Table 2). The carboxylation reaction of acetates of secondary alcohols $(\mathbf{1 b}-\mathbf{h})$ bearing TMS in the $\mathrm{R}^{1}$ position proceeded smoothly and afforded the corresponding carboxylic acids $(\mathbf{2} \mathbf{b}-\mathbf{h})$ in high isolated yields (entries 1-7). It is noteworthy that ester (1e), chloro (1f), terminal alkene (1g), and furan (1h) functionalities were compatible in the reaction (entries 4-7). When the carboxylation of acetates derived from tertiary alcohols was examined with $\mathrm{CoI}_{2}$ (phen), conversion of starting material remained low. In that case, $\mathrm{CoI}_{2}$ (bpy) was found to be a good catalyst and provided the carboxylated products $(2 \mathbf{i}-\mathbf{l})$ in good to high yields (entries 8-11). Amide functionality (11) was also tolerated in the reaction (entry 11). The acetate of primary propargylic alcohol (1m) also provided the corresponding carboxylic acid (2m) in moderate yield (entry 12). A substituent on the alkyne carbon of $\mathbf{1}\left(\mathrm{R}^{1}\right.$, Table 2) affects the carboxylation considerably. As the substituent $\mathrm{R}^{1}$ became less bulky, the yields of the carboxylated products (2) decreased; 1 n $\left(\mathrm{R}^{1}=\right.$ TBS, TBS = tert-butyldimethylsilyl $), 10\left(\mathrm{R}^{1}=\right.$ $\left.\mathrm{CMe}_{2}(\mathrm{OTBS})\right)$, 1p $\left(\mathrm{R}^{1}=t-\mathrm{Bu}\right)$, and $\mathbf{1 q}\left(\mathrm{R}^{1}=\mathrm{Cy}\right)$ afforded the corresponding products $(\mathbf{2 n}-\mathbf{q})$ in $88 \%, 55 \%, 57 \%$, and $26 \%$ yields, respectively (entries 13-16). Propargyl acetate having phenyl ring (1: $\mathrm{R}^{1}=\mathrm{Ph}, \mathrm{R}^{2}=\mathrm{Me}, \mathrm{R}^{3}=\mathrm{H}$ ) afforded the product in $9 \%$ yield. Substrate bearing terminal alkyne moiety $\left(\mathbf{1}: \mathrm{R}^{1}=\mathrm{H}, \mathrm{R}^{2}=\mathrm{Me}, \mathrm{R}^{3}=\mathrm{H}\right)$ did not provide the carboxylated product. ${ }^{12}$

The TMS group of the products in Table 2 could easily be removed via protodesilylation ${ }^{13}$ in the presence of a suitable base. In the case of $\alpha, \alpha$-disubstituted carboxylic acids such as $\mathbf{2 a}$, reaction with tetrabutylammonium fluoride (TBAF, $1.0 \mathrm{M}$ in THF) provided the corresponding carboxylic acid $\mathbf{2 r}$ in $78 \%$ yield (Scheme 1a). In contrast, when $\mathbf{2 a}$ or $\mathbf{2 d}$ were treated with $\mathrm{KOH}$ (crushed), carboxylic acids bearing an allenyl moiety $(\mathbf{2 s}, \mathbf{2 t})$ were selectively obtained in 
$80 \%$ and $65 \%$ yields, respectively (Scheme $1 \mathrm{~b}$ ). A similar reaction of $2 \mathbf{a}$ with $\mathrm{K}_{2} \mathrm{CO}_{3}$ resulted in the formation of a mixture of $\mathbf{2 r}$ and $2 \mathbf{s}$ $(\mathbf{2} \mathbf{r} / 2 \mathbf{s}=1 / 3)$. On the other hand, $\alpha, \alpha, \alpha$-trisubstituted carboxylic acids such as $2 \mathbf{i}$ and $2 \mathbf{j}$ reacted with $\mathrm{K}_{2} \mathrm{CO}_{3}$ to give $2 \mathbf{u}$ and $2 \mathbf{v}$ in $98 \%$ and $79 \%$ yields (Scheme 1c). Aryl and alkenyl carbons were introduced onto the terminal alkyne moiety of $\mathbf{2 u}$ and $2 \mathbf{v}$ by the Sonogashira coupling reaction $^{14 \mathrm{a}}$ ( $\mathbf{2 w}$ and $\mathbf{2 x}$, Scheme $1 \mathrm{~d}$ and $\left.1 \mathrm{e}\right)$. Moreover, $\mathrm{Au}-$ catalyzed intra-molecular cyclization ${ }^{14 \mathrm{~b}}$ of $2 \mathbf{v}$ provided unsaturated $\gamma$ lactone 2y smoothly (Scheme 1f). Thus these TMS moieties are very useful for the further derivatization.

When an optically pure $(S)$-1a was employed as the substrate in the present carboxylation, a racemic $2 \mathbf{a}$ was obtained in $72 \%$ yield (eqn (1)).

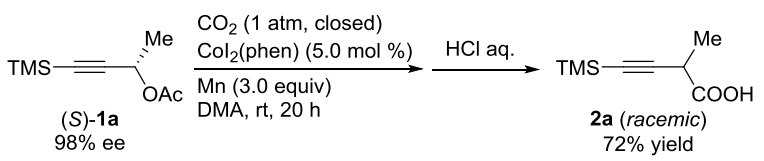

A plausible reaction mechanism is shown in Scheme 2. Initially, the reduction of a $\mathrm{Co}$ (II) complex with manganese affords a $\mathrm{Co}$ (I) catalyst species (A). Then, oxidative addition of a propargyl acetate (1) takes place via $\mathrm{C}-\mathrm{O}$ bond cleavage, giving a $\mathrm{Co}(\mathrm{III})$ intermediate (B) (step a). Subsequent reduction of propargyl $\mathrm{Co}$ (III) with manganese gives propargyl cobalt(II) species (C) (step b). ${ }^{3 a, b, 15}$ Then, the more nucleophilic $^{3 \mathrm{~b}} \mathrm{Co}(\mathrm{II})$ species (C) reacts with $\mathrm{CO}_{2}$ to give the carboxylatocobalt intermediate (D) (step c). Finally, the reduction of D with manganese affords the corresponding manganese carboxylate and the Co(I) catalytic species (A) regenerates (step d). Further studies about the reaction mechanism are now in progress.

We thank Professors Michinori Suginome and Toshimichi Ohmura (Kyoto University) for measuring optical rotations. This work was supported by Grant-in-Aid for Scientific Research on Innovative Areas ("Organic synthesis based on reaction integration" and "Molecular activation directed toward straightforward synthesis") from MEXT, Japan. K. N. is grateful to a Research Fellowship of JSPS for Young Scientists.

\section{Notes and references}

Department of Energy and Hydrocarbon Chemistry, Graduate School of Engineering, Kyoto University, Kyoto 615-8510, Japan, E-mail: ytsuji@scl.kyoto-u.ac.jp, Tel: (+81) 75-383-2514

$\dagger$ Electronic Supplementary Information (ESI) available: Experimental procedures and characterization data for all new compounds. See DOI: $10.1039 / \mathrm{c} 000000 \mathrm{x} /$

1 For reviews, see: (a) Y. Tsuji and T. Fujihara, Chem. Commun., 2012, 48, 9956-9964; (b) L. Zhang and Z. Hou, Chem. Sci., 2013, 4, 33953403; (c) K. Huang, C.-L. Sun and Z.-J. Shi, Chem. Soc. Rev., 2011, 40, 2435-2452; (d) M. Cokoja, C. Bruckmeier, B. Rieger, W. A. Herrmann and F. E. Kühn, Angew. Chem., Int. Ed., 2011, 50, 85108537; (e) S. N. Riduan and Y. Zhang, Dalton Trans., 2010, 39, 33473357.

2 (a) K. Ukai, M. Aoki, J. Takaya and N. Iwasawa, J. Am. Chem. Soc., 2006, 128, 8706-8707; (b) T. Ohishi, M. Nishiura and Z. Hou, Angew. Chem., Int. Ed., 2008, 47, 5792-5795; (c) J. Takaya, S. Tadami, K. Ukai and N. Iwasawa, Org. Lett., 2008, 10, 2697-2700; (d) C. S. Yeung and V. M. Dong, J. Am. Chem. Soc., 2008, 130, 7826-7827; (e) Hd. Ochiai, M. Jang, K. Hirano, H. Yorimitsu and K. Oshima, Org. Lett., 2008, 10, 2681-2683.

3 (a) T. Fujihara, K. Nogi, T. Xu, J. Terao, and Y. Tsuji, J. Am. Chem. Soc., 2012, 134, 9106-9109; (b) F. B. Sayyed, Y. Tsuji and S. Sakaki, Chem. Commun., 2013, 49, 10715-10717; (c) A. Correa and R. Martín, J. Am. Chem. Soc., 2009, 131, 15974-15975; (d) T. León, A. Correa and R. Martin, J. Am. Chem. Soc., 2013, 135, 1221-1224; (e) A. Correa, T. León and R. Martin, J. Am. Chem. Soc., 2014, 136, 1062-1069.

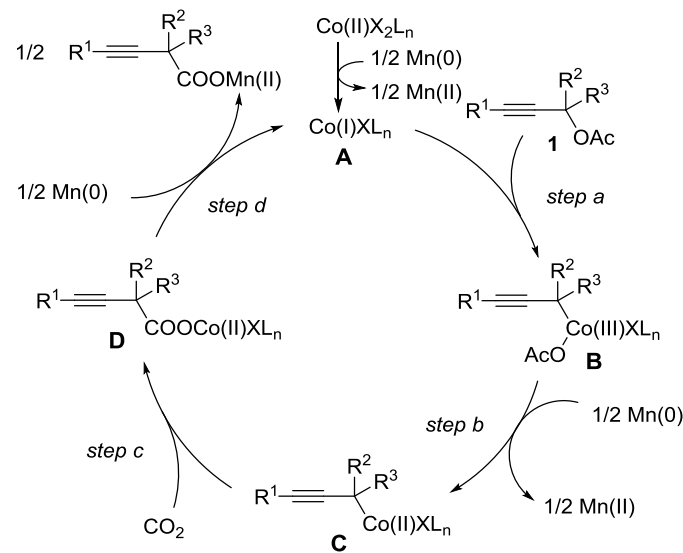

Scheme 2 Plausible catalyst cycle.

4 For another important $\mathrm{C}-\mathrm{C}$ bond forming reaction employing $\mathrm{CO}_{2}$, i.e., hydro- or heterocarboxylations, see: (a) T. Fujihara, T. Xu, K. Semba, J. Terao and Y. Tsuji, Angew. Chem., Int. Ed., 2011, 50, 523-527; (b) T. Fujihara, Y. Tani, K. Semba, J. Terao and Y. Tsuji, Angew. Chem., Int. Ed., 2012, 51, 11487-11490; (c) L. Zhang, J. Cheng, B. Carry and Z. Hou, J. Am. Chem. Soc., 2012, 134, 14314-14317; (d) S. Li, W. Yuan and S. Ma, Angew. Chem., Int. Ed., 2011, 50, 2578-2582; (e) C. M. Williams, J. B. Johnson and T. Rovis, J. Am. Chem. Soc., 2008, 130, 14936-14937; (f) J. Takaya and N. Iwasawa, J. Am. Chem. Soc., 2008, 130, 15254-15255; $(g)$ J. Takaya, K. Sasano and N. Iwasawa, Org. Lett., 2011, 13, 1698-1701.

5 (a) G. Courtois and L. Miginiac, J. Organomet. Chem., 1974, 69, 144; (b) G. R. Lappin, J. Am. Chem. Soc., 1949, 71, 3966-3968; (c) N. R. Pearson, G. Hahn and G. Zweifel, J. Org. Chem., 1982, 47, 3364 3366; (d) B. Miao and S. Ma, Chem. Commun., 2014, 50, 3285-3287.

6 (a) J. Tsuji, Palladium Reagents and Catalysts; Wiley: Chichester, UK, 2004; (b) B. M. Trost, Acc. Chem. Res., 1996, 29, 355-364; (c) B. M. Trost, Acc. Chem. Res., 1980, 13, 385-393.

7 D. Seebach, Angew. Chem., Int. Ed., 1979, 18, 239-258 and references cited therein.

8 (a) S. Torii, H. Tanaka, T. Hamatani, K. Morisaki, A. Jutand, F. Pfluger and J.-F. Fauvarque, Chem. Lett., 1986, 169-172; (b) M. J. Medeiros, C. Pintaric, S. Olivero and E. Dunach, Electrochimica Acta, 2011, 56, 4384-4389.

9 Recently, in the Ni-catalyzed carboxylation of benzylic chlorides with $\mathrm{CO}_{2}{ }^{3 \mathrm{~d}}{ }^{\text {d }} \mathrm{C}_{6} \mathrm{H}_{5} \mathrm{C} \equiv \mathrm{CCH}_{2} \mathrm{Cl}$ was used as a substrate and afforded $\mathrm{C}_{6} \mathrm{H}_{5} \mathrm{C} \equiv \mathrm{CCH}_{2} \mathrm{COOH}$ in only $29 \%$ yield; other propargylic substrates were not examined in the reaction.

$10 \mathrm{CoI}_{2}$ (phen) was synthesized by a similar method for $\mathrm{CoBr}_{2}$ (phen); G. Hilt, W. Hess, T. Vogler and C. Hengst, J. Organomet. Chem., 2005, 690, $5170-5181$.

11 See the Electronic Supplementary Information (ESI) for details.

12 In those cases including entries 14-16 in Table 2, most substrates were consumed and some oligomerizations occurred judging from GPC (gel permeation chromatography) analysis of the resulting reaction mixtures.

13 (a) C. Cai and A. Vasella, Helv. Chim. Acta, 1995, 78, 732-757; (b) L. T. Scott, M. J. Cooney and D. Johnels, J. Am. Chem. Soc., 1990, 112, 4054-4055.

14 (a) K. Sonogashira, J. Organomet. Chem., 2002, 653, 46-49; (b) H. Shi, L. Fang, C. Tan, L. Shi, W. Zhang, C.-C. Li, T. Luo and Z. Yang, J. Am. Chem. Soc., 2011, 133, 14944-14947.

15 X. Qian, A. Auffrant, A. Felouat and C. Gosmini, Angew. Chem., Int. Ed., 2011, 50, 10402-10405. 